\title{
Evaluasi pelatihan dokter puskesmas sebagai upaya peningkatan pengetahuan tentang rujukan penyakit non- spesialistik di Pekanbaru
}

\author{
Elda Nazriati ${ }^{1}$, Shelly Iskandar ${ }^{2}$, Fedri Rinawan ${ }^{3}$ \\ 1. Fakultas Kedokteran Universitas Riau; 2. Departemen Psikiatri Fakultas Kedokteran Universitas \\ Padjajaran; 3. Departemen IImu Kesehatan Masyarakat Fakultas Kedokteran Universitas \\ Padjadjaran
}

Korespondensi: Elda Nazriati, e-mail: eldanazriati@gmail.com

\begin{abstract}
Abstrak
Tujuan: Untuk mengevaluasi pelatihan dokter Puskesmas sebagai upaya peningkatan pengetahuan tentang rujukan penyakit non-spesialistik. Metode: Merupakan penelitian deskriptif analitik yang dilakukan secara retrospektif. Data diambil dari pelatihan dokter Puskesmas di Pekanbaru dengan materi yang dirancang oleh tim kendali mutu kendali biaya BPJS Provinsi Riau. Sampel penelitian adalah 32 peserta yang memenuhi kriteria inklusi. Evaluasi pelatihan dilakukan melalui pretest/posttest pengetahuan, kuesioner kepuasan peserta pelatihan, dan observasi. Hasil: Penelitian menunjukkan pengetahuan peserta setelah pelatihan lebih tinggi secara bermakna dibandingkan sebelum pelatihan $(p<0,05)$, tingkat kepuasan peserta terbanyak adalah kategori cukup puas $(62 \%)$, aspek kepuasan tertinggi adalah proses belajar. Beberapa masukan untuk perbaikan pelatihan antara lain waktu pelaksanaan, memperbanyak latihan keterampilan klinis, dan praktik dengan pasien nyata. Beberapa kendala yang dihadapi adalah penyesuaian jadwal narasumber, konsistensi kehadiran peserta, pelaksanaan ujian keterampilan klinik. Kesimpulan: Pelatihan dokter Puskesmas ini meningkatkan pengetahuan tentang penyakit non-spesialistik, tetapi proses pelaksanaannya perlu disempurnakan sesuai masukan peserta dengan mempertimbangkan kendala yang ada.
\end{abstract}

Kata kunci: pelatihan; dokter; evaluasi

\section{Abstract}

Objective: To evaluate the training of doctors in health centers as an effort to increase knowledge of non-specialists disease referral. Method: This was a descriptive analytic study conducted retrospectively. Data were taken from the health center physician training in Pekanbaru which designed by a team of quality control cost of Riau Province BPJS. Thirty-two participants who met the inclusion criteria took as the sample. Evaluation of training was done through a pretest/posttest knowledge, training participant satisfaction questionnaires, and observation. Result: It showed that the participants' knowledge after the training were significantly higher than before the training $(p<0.05)$. Most participants were quite satisfied (62\%); the highest satisfaction aspect was a learning process. Some inputs for the improvement of training were the time implementation, extending the exercise of clinical skills, and practice with real patients. Some of the obstacles faced was a resource schedule adjustments, consistency of attendance of the participants, and the implementation of the clinical skills exam. Conclusion: The training increases knowledge of the non-specialists disease, but the implementation process needs to be improved in accordance with participants input and considering the existing constraints.

Keywords: training; doctor; evaluation 


\section{PENDAHULUAN}

Tingginya angka rujukan sering dihubungkan dengan inefisiensi, buruknya layanan dan kegagalan mendiagnosis. Tingginya angka rujukan juga berdampak langsung pada pembiayaan kesehatan, karena itu rujukan pada layanan primer merupakan isu yang penting. ${ }^{1}$ Dalam sistem informasi BPJS, terdapat 144 penyakit yang apabila dirujuk didefinisikan sebagai rujukan non-spesialistik.

Salah satu indikator mutu pelayanan BPJS Kesehatan adalah rujukan kasus non spesialistik. Data sekunder BPJS Pekanbaru menunjukkan rerata rujukan nonspesialistik adalah 763 kasus per bulan. Penyakit non-spesialistik yang sering dirujuk adalah hipertensi esensial, diikuti oleh kelainan refraksi dan diabetes melitus, penyakit non spesialistik yang memerlukan tindakan seperti lipoma dan serumen prop juga sering dirujuk oleh dokter di Fasilitas Kesehatan Tingkat Pertama (FKTP). ${ }^{2}$

Sebagai dokter yang berpraktik di pintu gerbang pelayanan kesehatan, dokter di FKTP dituntut untuk kompeten dalam menapis dan menatalaksana penyakit nonspesialistik secara paripurna. Hasil penelitian di Pekanbaru menunjukkan bahwa sebagian dokter di FKTP sulit mempertahankan kompetensinya akibat kurang terlatih atau terpapar pada jenis penyakit tertentu. Beberapa kompetensi dokter perlu ditingkatkan dan disegarkan kembali. ${ }^{2}$

World Health Organization (WHO) sejak lama telah menghimbau untuk memperkuat layanan kesehatan primer. Saat ini penguatan layanan kesehatan primer merupakan salah satu prioritas nasional Indonesia untuk memperbaiki derajat kesehatan masyarakat. Salah satu komponen penting dalam penguatan tersebut adalah peningkatan kompetensi dokter yang bertugas di FKTP.

Dokter FKTP di Indonesia umumnya meningkatkan kompetensinya melalui seminar dan pelatihan yang sifatnya sporadis yang temanya ditentukan oleh penyelenggara. Pelatihan yang diikuti sesuai dengan kesempatan, kebutuhan individu, dukungan finansial, dan ketersediaan pelatihan. Pelatihan yang terstruktur, berkelanjutan, dan terevaluasi, yang ditekankan pada kebutuhan dokter di FKTP jarang dilakukan khususnya untuk menurunkan rujukan penyakit non-spesialistik.

Pekanbaru merupakan salah satu kota tempat uji coba pembayaran kapitasi berbasis komitmen pelayanan (KBK) yang dilakukan pada tahun 2015, di mana salah satu indikator kinerja yang diukur adalah rujukan kasus non-spesialistik. Uji coba KBK tersebut melibatkan seluruh Puskesmas di kota Pekanbaru yang berjumlah 20 Puskesmas. Evaluasi KBK menunjukkan berbagai penyebab rujukan non-spesialistik antara lain faktor administratif, fasilitas, manajemen pelayanan, dan kompetensi. $^{2}$

Sebagai tindak lanjut BPJS kesehatan di Pekanbaru telah melaksanakan pelatihan dokter Puskesmas yang salah satu 
tujuannya untuk menurunkan rujukan penyakit non-spesialistik. Dari 72 orang dokter yang bertugas di rawat inap dan rawat jalan Puskesmas di Pekanbaru diundanglah 40 orang dokter yang merupakan perwakilan dari 20 Puskesmas. Dari 40 orang dokter yang diundang, 38 orang yang mengikuti pelatihan. Pelaksanaan pelatihan ini perlu dievaluasi untuk peningkatan kualitas pelatihan di masa yang akan datang. Fokus penelitian ini ditekankan pada alur Quality Improvement atau proses peningkatan mutu penyelenggaraan yang meliputi aspek input, proses dan output khususnya pada pelayanan yang berkaitan langsung dengan pembelajaran atau pelayanan akademik pelatihan.

\section{METODE}

Penelitian ini merupakan studi deskriptif analitik untuk mengevaluasi pelatihan dokter Puskesmas. Penelitian dilakukan secara retrospektif menggunakan data pelatihan Dokter Puskesmas yang diselenggarakan atas biaya dari BPJS Kesehatan Pekanbaru pada bulan Agustus sampai Oktober 2015. Modul pelatihan adalah modul yang dibuat oleh TKMKB Provinsi Riau. Modul disusun berdasarkan penyakit non-spesialistik yang banyak dirujuk di Kota Pekanbaru, telah melalui pembahasan bersama dokter-dokter spesialis yang akan menjadi narasumber dan pihak BPJS, serta pernah dipresentasikan pada Pertemuan IImiah Tahunan (PIT) Perhimpunan Dokter Keluarga Indonesia tahun 2015. Seluruh proses pelatihan direkam dalam bentuk video pelatihan. Pelatihan dilakukan oleh panitia yang ditunjuk khusus dengan Surat Keputusan Bersama Kepala Divisi Regional II BPJS dan Dekan Fakultas Kedokteran Universitas Riau (FKUR). Seluruh dokumen pelatihan diarsipkan oleh panitia.

Pelatihan dilakukan di Hotel Pangeran Pekanbaru setiap hari Jumat dan Sabtu selama 18 hari. Program pelatihan dan rincian kegiatan harian disajikan pada Tabel 1 dan 2.

Tabel 1. Materi pelatihan dokter puskesmas.

\begin{tabular}{llllll}
\hline $\begin{array}{l}\text { Hari 1 } \\
\text { Manajemen }\end{array}$ & Hari 2 & Hari 3 Bedah & Hari 4 & Hari 5 & Pari 6 \\
FKTP & TB & & TB & Hatri & Paru (selain TB) \\
\hline $\begin{array}{l}\text { Hari 7 } \\
\text { lifestyle }\end{array}$ & Hari 8 & Hari 9 & Hari 10 & Hari 11 & Hari 12 \\
& Mata & Reproduksi & THT & Dermatologi & Penyakit Anak \\
\hline $\begin{array}{l}\text { Hari 13 } \\
\text { Febris }\end{array}$ & Hari 14 & Hari 15 & Hari 16 & Hari 17 & Hari 18 \\
& Neurologi & Keterampilan & Emergency & System rujukan & evaluasi \\
& & klinis & & & \\
\hline
\end{tabular}

Populasi penelitian ini adalah 38 orang dokter Puskesmas yang mengikuti pelatihan. Peserta yang memenuhi kriteria inklusi dan tidak memenuhi kriteria eksklusi dipilih sebagai sampel penelitian yang berjumlah 32 orang. Adapun kriteria inklusi sampel penelitian adalah mengikuti kegiatan pelatihan minimal $75 \%$, sedangkan kriteria eksklusi adalah tidak mengisi kuesioner kepuasan, tidak 
mengikuti minimal 75\% seluruh pretest dan posttest yang dilaksanakan.

Data penelitian terdiri atas data input, proses, dan output. Data input meliputi persiapan pelatihan. Data proses terdiri dari pelaksanaan pelatihan. Sedangkan data output terdiri dari kepuasan peserta pelatihan, serta data pretest dan posttest pengetahuan terkait materi pelatihan.
Data persiapan pelatihan meliputi persiapan modul, panitia, narasumber, dan peserta. Data dikumpulkan melalui lembar tilik observasi. Data proses meliputi kehadiran peserta dan narasumber, kesesuaian jalannya pelatihan dengan modul pelatihan, serta kendala yang dihadapi. Data dikumpulkan melalui lembar tilik observasi, dan melihat rekaman video pelatihan.

Tabel 2. Contoh rincian kegiatan harian (hari ke dua).

\begin{tabular}{|c|c|c|}
\hline Waktu & Kegiatan & Keterangan \\
\hline $08.00-8.15$ & Pengantar & Panitia \\
\hline $8.15-8.30$ & Pretest 2 & panitia \\
\hline $9.30-9.15$ & $\begin{array}{l}\text { Kasus penyakit dalam (HT,DM, dispepsia, artritis) dan prinsip } \\
\text { penatalaksanaannya di FKTP }\end{array}$ & Sp.PD \\
\hline $9.15-9.30$ & istirahat & \\
\hline $9.30-10.30$ & Pemberian skenario dan diskusi kelompok & Panitia \\
\hline $10.30-11.30$ & Presentasi kasus1 (hipertensi) + diskusi & Pembahas :Sp.PD \\
\hline $11.30-12.30$ & Presentasi kasus $2(\mathrm{DM})+$ diskusi & Pembahas :Sp.PD \\
\hline $12.30-13-30$ & istirahat & \\
\hline $13.30-14.30$ & Presentasi kasus 3 (dispepsia) + diskusi & Pembahas :Sp.PD \\
\hline $14.30-15.30$ & Presentasi kasus 4 (artritis) + diskusi & Pembahas :Sp.PD \\
\hline $15.30-15.45$ & Post test 2 & Panitia \\
\hline
\end{tabular}

Data kepuasan peserta pelatihan dikumpulkan melalui kuesioner yang dibuat oleh peneliti yang diuji validitas dan reliabilitas menggunakan model pengukuran satu kali (single trial administration), didapatkan Cronbach's alpha 0,952. Terdapat 23 pernyataan yang dinyatakan valid (item total correlation $>r$ tabel 0,361). Kuesioner berisi pernyataan tentang kepuasan peserta yang dijawab dengan skor 1 (sangat tidak puas) sampai dengan skor 5 (sangat puas) yang diisi peserta selama 15 menit setelah pelatihan selesai. Kuesioner juga berisi pertanyaan terbuka yang akan diisi peserta dalam bentuk narasi. Data kepuasan peserta pelatihan selanjutnya dikategorikan menjadi tingkat kepuasan baik jika $X>($ mean+SD), tingkat kepuasan cukup jika (mean-SD) $\leq X \leq($ mean $+S D)$, dan tingkat kepuasan kurang jika $\mathrm{X}<($ mean-SD).

Pretest dan posttest dilakukan setiap hari pelatihan pada awal sesi dan akhir sesi pelatihan. Soal pretest dan posttest dibuat oleh narasumber, selanjutnya panitia akan memeriksa hasil tes tersebut berdasarkan kunci jawaban yang diberikan oleh pembuat soal. Data pretest tiap peserta adalah rerata nilai pretest peserta tersebut selama pelatihan, data posttest tiap peserta adalah rerata nilai posttest peserta tersebut selama. Uji normalitas menunjukkan bahwa data terdistribusi normal sehingga digunakan uji $t \quad 2$ 
kelompok berpasangan untuk mengetahui apakah terdapat perbedaan pengetahuan sebelum dan sesudah pelatihan.

Data persiapan pelatihan, pelaksanaan pelatihan, dan narasi pendapat peserta tentang pelatihan, di-input, dan dikategorikan sesuai dengan tema-tema penelitian, selanjutnya disajikan dalam bentuk naratif di dalam tabel.

Penelitian ini sudah lolos kaji etik dari unit etik penelitian kedokteran dan kesehatan
Fakultas Kedokteran Universitas Riau (No.261/UN.19.5.1.1.8/UEPKK/2017).

\section{HASIL DAN PEMBAHASAN}

\section{Gambaran tentang persiapan dan pelaksanaan pelatihan dokter puskesmas}

Berdasarkan data penelitian didapatkan persiapan pelatihan yang meliputi persiapan modul, narasumber, panitia, dan peserta yang disajikan pada Tabel 3:

Tabel 3. Gambaran persiapan pelatihan dokter puskesmas.

\begin{tabular}{|c|c|c|}
\hline No & Observasi & Deskripsi \\
\hline \multirow[t]{4}{*}{1.} & persiapan modul & $\begin{array}{l}\text { Modul disusun sesuai prioritas : penyakit non spesialistik yang banyak } \\
\text { dirujuk berdasarkan data BPJS Pekanbaru }\end{array}$ \\
\hline & & Durasi disesuaikan dengan dana yang difasilitasi BPJS \\
\hline & & $\begin{array}{l}\text { Materi disusun melalui diskusi dengan perwakilan dokter Puskesmas, } \\
\text { pengurus PDKI, pihak BPJS, dan urgensi lain berdasarkan data dinas } \\
\text { kesehatan Pekanbaru }\end{array}$ \\
\hline & & Dipresentasikan pada PIT PDKI untuk mendapat masukan. \\
\hline \multirow[t]{3}{*}{2.} & Persiapan panitia & $\begin{array}{l}\text { Pembentukan panitia yang terdiri dari unsur fakultas kedokteran, rumah } \\
\text { sakit pendidikan, dan pihak BPJS kesehatan }\end{array}$ \\
\hline & & Pembuatan proposal pelatihan ke pihak BPJS \\
\hline & & Rapat teknis panitia, persiapan tempat dan setting ruangan \\
\hline \multirow[t]{4}{*}{3.} & $\begin{array}{l}\text { Persiapan } \\
\text { narasumber }\end{array}$ & $\begin{array}{l}\text { Narasumber adalah dosen Fakultas Kedokteran Universitas Riau yang } \\
\text { relevan, dokter staf BPJS yang menguasai sistem pelayanan }\end{array}$ \\
\hline & & Penjelasan tentang tujuan, metode, hak dan kewajiban narasumber. \\
\hline & & Meminta kesediaan narasumber melalui departemen (bagian) terkait. \\
\hline & & Sebagian narasumber meminta untuk melalui jalur organisasi profesi. \\
\hline \multirow[t]{2}{*}{4.} & Persiapan peserta & $\begin{array}{l}\text { Peserta adalah dokter yang bertugas sebagai pemberi pelayanan } \\
\text { kesehatan di Puskesmas, peserta diundang melalui dinas kesehatan, } \\
\text { mendapat izin dari atasan. }\end{array}$ \\
\hline & & $\begin{array}{l}\text { Peserta diinformasikan tentang fasilitas pelatihan (tempat, konsumsi, } \\
\text { sertikat dengan akreditasi IDI) }\end{array}$ \\
\hline
\end{tabular}

Aspek yang diobservasi untuk melihat gambaran pelaksanaan pelatihan meliputi kehadiran peserta, keaktifan peserta, kehadiran narasumber, kesesuaian materi yang disajikan dengan isi modul pelatihan, kesesuaian metode pelatihan, kendala yang dihadapi, serta masukan dari peserta, seperti yang disajikan pada Tabel 4.
Penyelenggaraan pelatihan memerlukan persiapan yang matang, beberapa hal yang harus dipertimbangkan dalam merencanakan dan mengimplementasikan pelatihan adalah menentukan kebutuhan pelatihan, menentukan hasil pembelajaran, menentukan materi pelatihan, menentukan peserta, 
menentukan jadwal yang terbaik, memilih fasilitas yang sesuai, memilih pelatih yang sesuai, memilih dan mempersiapkan alat bantu audiovisual, mengkoordinasikan program pelatihan, dan mengevaluasi program. ${ }^{3}$ Kebutuhan pelatihan dapat ditentukan dengan menanyakan pada peserta, menanyakan pada pengguna, menanyakan pada orang yang pekerjaannya berhubungan dengan topik pelatihan, melakukan test dan menganalisis performa peserta. ${ }^{3}$ Pelatihan dokter di layanan primer sering tidak terstruktur, fokus pada pelatihan spesialistik yang terfragmentasi. Topiktopik seperti kerja tim, etik, komunikasi, profesionalisme, yang penting untuk memberikan pelayanan berkualitas jarang mendapat perhatian. ${ }^{4}$

Tabel 4. Gambaran pelaksanaan pelatihan.

\begin{tabular}{|c|c|c|}
\hline No & Observasi & Deskripsi \\
\hline \multirow[t]{2}{*}{1.} & kehadiran peserta & Tingkat kehadiran $90,5 \%$ \\
\hline & & $\begin{array}{l}\text { Beberapa peserta datang terlambat dan meminta izin tidak mengikuti } \\
\text { pelatihan sampai selesai karena alasan tugas kedinasan dan } \\
\text { kepentingan pribadi }\end{array}$ \\
\hline 2. & Keaktifan peserta & $\begin{array}{l}\text { Rerata } 2-3 \text { orang dalam kelompok terlihat aktif bertanya dan } \\
\text { menanggapi }\end{array}$ \\
\hline \multirow[t]{5}{*}{3.} & $\begin{array}{l}\text { Kehadiran } \\
\text { narasumber }\end{array}$ & $\begin{array}{l}\text { Terdapat } 1 \text { subtopik manajemen FKTP yang dibatalkan karena tidak } \\
\text { tersedianya narasumber. }\end{array}$ \\
\hline & & $\begin{array}{l}\text { Topik lifestyle tidak dilaksanakan karena perpindahan jadwal } \\
\text { narasumber yang tidak bisa diakomodir. }\end{array}$ \\
\hline & & durasi kehadiran narasumber sesuai dengan alokasi waktu, \\
\hline & & Alasan ketidakhadiran terutama berbenturan dengan kegiatan lainnya \\
\hline & & $\begin{array}{l}\text { Beberapa topik dilakukan peubahan jadwal menyesuaikan dengan } \\
\text { ketersediaan waktu narasumber. }\end{array}$ \\
\hline 4. & $\begin{array}{l}\text { kesesuaian materi } \\
\text { dengan isi modul } \\
\text { pelatihan }\end{array}$ & $\begin{array}{l}\text { Umumnya semua narasumber sudah mengisi materi pelatihan sesuai } \\
\text { topik yang direncanakan. Terdapat beberapa perubahan subtopik sesuai } \\
\text { masukan dari narasumber }\end{array}$ \\
\hline \multirow[t]{2}{*}{5.} & $\begin{array}{l}\text { Kesesuaian metode } \\
\text { pembelajaran }\end{array}$ & $\begin{array}{l}\text { Beberapa topik penyajikan materi terlalu banyak sehingga waktu diskusi } \\
\text { kelompok lebih sedikit }\end{array}$ \\
\hline & & $\begin{array}{l}\text { Karena keterbatasan waktu dan fasilitas, latihan keterampilan klinik } \\
\text { hanya bersifat demonstrasi oleh narasumber, } \\
\text { keterampilan klinik dievaluasi dengan ujian tulis }\end{array}$ \\
\hline 6. & $\begin{array}{l}\text { kendala yang } \\
\text { dihadapi }\end{array}$ & $\begin{array}{l}\text { Konsistensi kehadiran peserta, komitmen waktu dan panitia, variasi } \\
\text { pemahaman narasumber terhadap tujuan dan metode pelatihan, fasilitas } \\
\text { dan waktu untuk latihan keterampilan klinik }\end{array}$ \\
\hline \multirow[t]{2}{*}{7.} & Masukan peserta & $\begin{array}{l}\text { Pelatihan dilakukan tidak di akhir minggu, beberapa subtopik diganti } \\
\text { dengan kasus yang lebih banyak di FKTP }\end{array}$ \\
\hline & & $\begin{array}{l}\text { Durasi pelatihan yang menyita waktu, pelatihan menghadirkan pasien } \\
\text { nyata, Pembuatan SOP lebih banyak dibahas bersama narasumber }\end{array}$ \\
\hline
\end{tabular}

Beberapa hal yang perlu dipertimbangkan dalam menentukan peserta adalah siapa yang akan memperoleh manfaat pelatihan, program apa yang dibutuhkan oleh pemerintah, apakah pelatihan bersifat sukarela atau wajib, apakah peserta harus dari tingkatan jabatan tertentu, apakah dua atau lebih tingkatan jabatan harus berada dalam satu kelas. ${ }^{3}$ 
Seperti yang tampak pada Tabel 3, panitia telah berusaha mempersiapkan pelatihan, pada kenyataannya masih terdapat beberapa hal yang tidak sesuai dengan perencanaan seperti yang disajikan pada Tabel 4. Meskipun rerata kehadiran peserta sebanyak 97\%, masih terdapat 6 orang peserta dengan presentasi kehadiran di bawah 75\%, beberapa hal yang menyebabkan ketidakhadiran peserta pelatihan adalah tugas kedinasan atau urusan pribadi yang tidak bisa ditinggalkan.

Keaktifan peserta ditentukan oleh metode pembelajaran yang dipilih, pelatihan ini menggunakan metode ceramah dan diskusi kelompok sebagai metode pembelajaran utama, metode ceramah dapat membosankan, dan tidak bermanfaat jika narasumber hanya menceritakan kembali sebuah teks standar dan tidak berfungsi secara adekuat untuk mengembangkan pemahaman dan memotivasi peserta untuk belajar. Metode ceramah juga dapat mendatangkan sikap yang pasif. ${ }^{5}$

Salah satu metode yang membuat peserta aktif sekaligus mengatasi kendala ketersediaan waktu pelatihan adalah pembelajaran secara online. Beberapa keuntungan antara lain ketersediaan waktu dan kemudahan mencapai lokasi pelatihan, meningkatkan kemampuan penggunaan komputer, dan lebih murah, tetapi beberapa kendala yang mungkin dihadapi adalah peserta akan terisolasi di tempatnya, beban kerja panitia untuk melayani komentar tiap peserta, teknologi baru yang memerlukan penyesuaian, tidak dapat melaksanakan workshop secara langsung, membutuhkan komputer dan internet dengan persyaratan tertentu. Penelitian yang dilakukan pada tahun 2011 menunjukkan bahwa dokter berusia muda lebih menyukai pembelajaran online, sedangkan dokter berusia tua lebih memilih pembelajaran di dalam kelas. ${ }^{6}$

Kehadiran narasumber dan kesesuaian metode sangat ditentukan oleh beberapa faktor, antara lain narasumber yang dipilih dan kesesuaian waktu. Seleksi narasumber atau instruktur merupakan hal yang penting bagi suksesnya program pelatihan, beberapa hal yang menjadi pertimbangan adalah kualifikasi, komitmen untuk mengajar, kemampuan berkomunikasi, berorientasi pada peserta, kemampuan menyesuaikan dengan tujuan yang akan dicapai. Selain itu pemilihan narasumber juga terkait dengan kemampuan dana. Beberapa cara untuk memilih instruktur adalah dengan melihat performa pada situasi yang sama, atau menerima rekomendasi dari pelatihan lain yang pernah menggunakan narasumber tersebut. $^{3}$

Pada Tabel 4, disebutkan bahwa salah satu masukan peserta adalah belajar dengan pasien nyata. Pasien dan keluarganya merupakan sumber pembelajaran yang potensial. Pasien dan keluarganya dapat diikutsertakan dalam pembelajaran melalui berbagai macam format seperti melibatkan pasien untuk berbagi pengalaman tentang layanan kesehatan pada pasien dengan penyakit serius 
misalnya stroke, transplantasi organ, dan kanker, atau pasien yang berpengalaman dalam hal membuat keputusan yang berhubungan dengan masalah etik kesehatan, ${ }^{7}$ akan tetapi persiapan untuk melaksanakan pembelajaran berbasis komunitas memerlukan persiapan yang matang, antara lain persiapan pembimbing, teknis pelaksanaan, pasien, dan peserta. Peserta perlu diberikan informasi yang jelas tentang perkiraan kehadiran, jadwal, penilaian, apa yang akan dilakukan, serta fasilitas yang tersedia. ${ }^{8}$ Penelitian Neiman (2011) menunjukkan, belajar bersama pasien menggunakan refleksi kasus, portofolio, presentasi, dan ringkasan kasus cukup efektif untuk meningkatkan kemampuan diagnosis dan keterampilan komunikasi. ${ }^{9}$ Seorang dokter penting mempelajari bagaimana persepsi pasien penyakit kronis, dan pengaruh penyakit terhadap kondisi fisik dan mentalnya. ${ }^{9}$ Beberapa tantangan yang mungkin dihadapi adalah ketersediaan sumber daya seperti supervisi dan fasilitas pembelajaran. ${ }^{4}$

\section{Pengetahuan peserta pelatihan dokter puskesmas dan tingkat kepuasan peserta}

Untuk mengetahui apakah terdapat perbedaan pengetahuan sebelum dan sesudah pelatihan dilakukan $u j i \quad t$ berpasangan yang hasilnya digambarkan pada Tabel 5.

Tabel 5 menunjukkan pengetahuan peserta sesudah pelatihan lebih tinggi secara bermakna dibandingkan pengetahuan sebelum pelatihan. Dilihat dari metode pembelajaran yang digunakan, yaitu metode ceramah dan diskusi peningkatan pengetahuan ini cukup beralasan, karena tujuan utama metode ceramah adalah menyampaikan cakupan atau ulasan sebuah topik, pengertian sebuah proses atau fenomena. Metode ceramah dapat menjadi menu utama pada topik-topik yang sulit, gambaran umum sebuah topik, perbedaan pandangan terhadap sebuah subyek, simpulan atau temuan terbaru, dan laporan pengalaman klinik atau laboratorium. Metode ceramah dapat digunakan untuk membangkitkan pemikiran dan pemahaman yang lebih mendalam untuk meningkatkan pemikiran klinik atau ilmiah. Ceramah dapat menjadi penuntun untuk mempelajari sebuah topik atau prosedur sehingga peserta dapat meninjau kembali dan dapat mengembangkan apa yang sudah dipelajarinya secara mandiri. ${ }^{4}$

Tabel 5. Uji Perbedaan rerata nilai Pretest dan Posttest

\begin{tabular}{ccccc}
\hline \multicolumn{2}{c}{ Pre test } & \multicolumn{2}{c}{ Post test } & p \\
$\mathrm{n}$ & Rerata $\pm \mathrm{sd}$ & $\mathrm{n}$ & Rerata $\pm \mathrm{sd}$ & $\mathbf{p}$ \\
\hline \multirow{2}{*}{32} & $\begin{array}{c}3,718 \pm \\
\text { 0,247 }\end{array}$ & 32 & $\begin{array}{c}4,541 \pm \\
0,210\end{array}$ & 0,000 \\
\hline
\end{tabular}

Tingkat kepuasan peserta pelatihan berdasarkan pengisian kuesioner kepuasan adalah seperti yang disajikan pada Gambar 1.

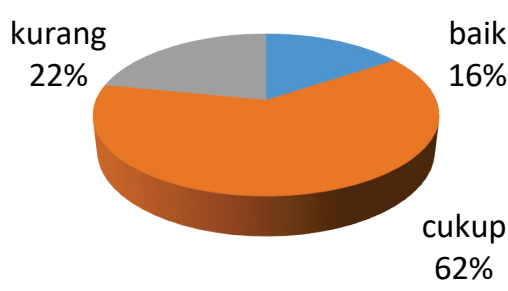

Gambar 1. Tingkat kepuasan peserta pelatihan 
Sedangkan gambaran rerata kepuasan peserta pelatihan berdasarkan aspek kepuasan disajikan pada Gambar 2.

Pada Gambar 1 tampak bahwa kepuasan peserta terbanyak pada kategori cukup puas (62\%), sebagian peserta merasa sangat puas (16\%), dan kurang puas (22\%).

Berdasarkan item pernyataan yang mendapat skor rerata cukup tinggi $(\geq 4,75)$ pada kuesioner, beberapa faktor yang kemungkinan meningkatkan kepuasan antara lain kesempatan untuk bertanya, tempat pelatihan, metode pembelajaran ceramah dan diskusi, serta pengetahuan tentang edukasi pasien dan keluarganya. Sedangkan beberapa hal yang kemungkinan menurunkan kepuasan (skor rerata $\leq 4,21$ ) antara lain pembuatan SOP, kejelasan petunjuk pelaksanaan, dan waktu yang digunakan untuk pelatihan.

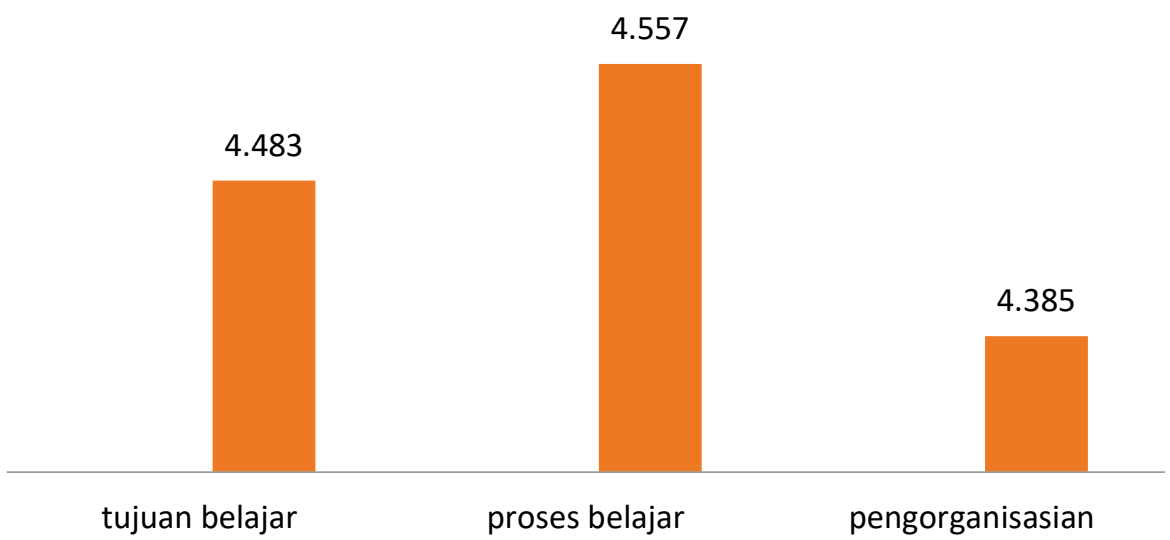

Gambar 2. Rerata kepuasan berdasarkan aspek kepuasan peserta.

Metode utama yang digunakan pada pelatihan ini adalah metode ceramah dan diskusi kasus. Penggunaan metode ini membuat peserta mendapat banyak kesempatan untuk bertanya, mengeksplorasi pengetahuan berdasarkan kasus yang didiskusikan menyegarkan kembali pengetahuan yang telah ada dan menerapkannya pada kasus, termasuk bagaimana cara mengedukasi pasien dan keluarganya sesuai kasus. Tempat pelatihan yang cukup nyaman membantu mengurangi kejenuhan peserta.

Pelatihan ini menggunakan metode diskusi kasus dan penugasan pembuatan SOP. Dengan penugasan ini diharapkan melatih peserta untuk membuat panduan yang dapat digunakan di tempat kerjanya. Salah satu penyebab masih tingginya angka rujukan adalah tidak adanya panduan yang dapat dipedomani. ${ }^{10}$ Metode ini sedikit berbeda dengan metode program pendidikan kedokteran berkelanjutan yang biasa diikuti peserta yang umumnya menggunakan metode ceramah. Kejelasan tentang prosedur pelaksanaan metode ini sangat menentukan kelancaran kegiatan.

Waktu pelatihan yang cukup panjang dan kegiatan harian yang cukup padat akan meningkatkan kejenuhan dan mengurangi kesempatan untuk melaksanakan kegiatan kedinasan dan kegiatan pribadi peserta. 
Hal-hal lain yang diduga mengurangi kepuasan peserta adalah seperti yang disebutkan dalam masukan peserta yaitu beberapa sub-topik diganti dengan kasus yang lebih banyak di FKTP, pelatihan menghadirkan pasien nyata, dan pembuatan SOP lebih banyak dibahas bersama narasumber.

Pelatihan ini dibiayai oleh BPJS kesehatan sehingga pelaksanaannya terikat pada tahun anggaran, hal ini menyebabkan pelaksanaan kegiatan disesuaikan dengan waktu pencairan dana dan pelaporannya. Sebaiknya kegiatan pelatihan selanjutnya lebih memperhatikan waktu pelatihan dengan periode pelatihan lebih panjang yang berisi waktu libur di antara sesi pelatihan. Sehingga mengurangi kejenuhan dan memberi kesempatan peserta menyelesaikan agenda pribadinya.

\section{KESIMPULAN}

Pengetahuan peserta setelah pelatihan lebih tinggi secara bermakna dibandingkan sebelum pelatihan $(p<0,05)$, tingkat kepuasan peserta terbanyak adalah kategori cukup puas (62\%), dimana aspek kepuasan tertinggi adalah proses belajar. Beberapa masukan untuk perbaikan pelatihan antara lain waktu pelaksanaan, memperbanyak latihan keterampilan klinis, dan praktik dengan pasien nyata. Beberapa kendala yang dihadapi adalah penyesuaian jadwal narasumber, konsistensi kehadiran peserta pelatihan, pelaksanaan ujian keterampilan klinik.

\section{UCAPAN TERIMA KASIH}

Penulis mengucapkan terima kasih kepada BPJS Pekanbaru dan perhimpunan dokter keluarga Indonesia cabang Riau yang memfasilitasi terlaksananya penelitian ini.

\section{KONFLIK KEPENTINGAN}

Peneliti merupakan anggota panitia pelatihan, namun pada penelitian ini data yang diambil adalah data obyektif yang terukur dan terdokumentasi, sehingga diharapkan meminimalisir unsur subjektivitas.

\section{DAFTAR PUSTAKA}

1. British Medical Association Health Policy and Economic Research Unit; British Medical Association. Factors capable of influencing an increase in GP referral rates to secondary care (England only). London: British Medical Association; 2009.

2. Nazriati E. Profil Rujukan Kasus Non Spesialistik pada Fasilitas Kesehatan Tingkat Primer di Kota Pekanbaru-Riau; Jurnal Kesehatan Masyarakat Nasional 2015; 9(4):327-332.

3. Kirkpatrick DL, Kirkpatrick JD. Evaluating Taining Program. Berrett-Koehler Publishers; 2009.

4. Sein NN, Tumbo J. Determinants of effective medical intern training at a training hospital in North West Province, South Africa. African journal of health professions education $2012 ; 4(1): 10$ 14. DOI:10.7196/AJHPE.100.

5. Dent AJ, Harden RM, A Practical Guide for Medical Teachers. 3rd Ed. US: Elsevier Limitted; 2009. 
6. Giamto WK. Empowering Rural-Remote Doctors Through Distance Cme: A Literature Study. Jurnal Pendidikan Kedokteran Indonesia. 2016; 5(1):45-52.

7. Familycentredcare.org Home Care, Health Care and End of Life Care, The Family Caregiver Handbook, (cited 2009 July 12) Available from: http://www.familycentredcare.org.

8. Berlin A, Carter F. Teaching \& Learning in The Community. Introduction of Deanery's new web based learning package for clinical teachers (cited 2009 July 24). Available from http://www.gmc-uk.org.

9. Nieman ZL, Cheng L. Chronic illness needs educated doctors: An innovative primary care training program for chronic illness education. Medical Teacher. 2011;33:6,e340-e348, DOI:10.3109/0142159X.2011.558532.

10. Evans $\mathrm{E}$, Aiking $\mathrm{H}$, Edwards $\mathrm{A}$. Reducing variation in general practitioner referral rates through clinical engagement and peer review of referrals: a service improvement project. Quality in Primary Care. 2011; 19(4):263-72. 